Audiology

\title{
Cochlear implant in prelingually deafened oralist adults: speech perception outcomes, subjective benefits and quality of life improvement
}

\author{
Impianto cocleare in adulti con ipoacusia prelinguale e riabilitazione di tipo \\ oralista: percezione del linguaggio, benefici soggettivi e miglioramento \\ della qualità della vita \\ F. FORLI ${ }^{1}$, G. TURCHETTI ${ }^{2}$, G. GIUNTINI ${ }^{1}$, S. BELLELLI ${ }^{2}$, S. FORTUNATO ${ }^{1}$, L. BRUSCHINI $^{1}$, M.R. BARILLARI $^{3}$,
S. BERREITINI $I^{1,4}$ \\ ${ }^{1}$ ENT, Audiology and Phoniatric Unit, University of Pisa, Italy; ${ }^{2}$ Istituto di Management, Scuola Superiore Sant'Anna, \\ Pisa, Italy; ${ }^{3}$ Dipartimento di Salute Mentale e Fisica e Medicina Preventiva, Divisione di Audiologia e Foniatria, \\ II Università di Napoli, Italy; ${ }^{4}$ Department of Clinical Science, Intervention and Technology, Karolinska Institutet, \\ 17177, Stockholm, Sweden
}

\begin{abstract}
SUMMARY
The aim of this study is to report our results in a group of prelingually deafened adults, who followed an oralist rehabilitation programme, and submitted to cochlear implant at our institution. We evaluated 30 prelingually deafened adult patients, 18 males and 12 females, median age 35 years, of a group of 36 prelingually deafened adult patients consecutively submitted to unilateral cochlear implantation at the ENT Unit of the University of Pisa. After implantation, patients achieved significant benefits in terms of speech perception skills, including the ability to have telephone conversations in some cases, quality of life and their own perception of disability. According to literature data, the results herein reported are quite variable but generally satisfactory. Procedures other than traditional speech perception measures should be used to evaluate the benefits of cochlear implant in such patients, to compressively evaluate the global benefits, not only in terms of speech perception, but also in terms of quality of life and daily life.
\end{abstract}

KEY WORDS: Prelingual deafness • Cochlear implant • Quality of life

\section{RIASSUNTO}

Lo scopo di questo studio è riportare i risultati ottenuti in un gruppo di pazienti adulti con ipoacusia prelinguale, che hanno seguito un programma di riabilitazione di tipo oralista, sottoposti ad impianto cocleare nella nostra clinica. Sono stati analizzati 30 pazienti adulti, 18 maschi e 12 femmine, con un'età media di 35 anni, selezionati da un gruppo di 36 adulti con sordità prelinguale sottoposti ad impianto cocleare unilaterale nella U.O. Otorinolaringoiatria, Foniatria ed Audiologia Universitaria di Pisa. Dopo la procedura di impianto cocleare i pazienti hanno raggiunto significativi benefici in termini di percezione del linguaggio, inclusa la capacità di avere una conversazione telefonica in qualche caso; benefici sono stati raggiunti anche riguardo la qualità della vita e la percezione della propria disabilità. In accordo con i dati riportati in letteratura i risultati da noi presentati sono variabili ma generalmente soddisfacenti. Per valutare $i$ benefici dell'impianto cocleare nei pazienti riportati in questo studio devono essere considerate altre procedure oltre a quelle tradizionali di valutazione della percezione verbale, così da poter apprezzare complessivamente i benefici, non solo in termini di percezione verbale ma anche di miglioramento della qualità della vita quotidiana.

PAROLE CHIAVE: Sordità prelinguale • Impianto cocleare • Qualità della vita

Acta Otorhinolaryngol Ital 2017;37:416-422

\section{Introduction}

Cochlear implantation is the treatment of choice for patients affected with severe to profound sensorineural hearing loss ${ }^{1-5}$. Until the mid 1990s, these patients were considered poor CI candidates, because improvement in speech perception was limited. However, several recent studies have suggested that the latest implant technology results in open-set speech per- ception abilities, although variability among individuals was great and performance lagged behind that of post-lingually deafened adults ${ }^{6-10}$. These conclusions are mainly based on results obtained in small and heterogeneous samples ${ }^{7811} 12$. It is useful to underscore that in Italy since the sixties oralism has been the main rehabilitative choice for patients suffering with preverbal deafness. As a consequence, in Italy the vast majority of adult patients with preverbal 
deafness seeking a CI consistently using hearing aids, have been following an oralist rehabilitation mode and developed oral language, even if at variable degrees of performance.

The aim of this study was to report our results in a group of 30 prelingually deafened adults, who followed an oralist rehabilitation program, and submitted to $\mathrm{CI}$ in our institution. Gains in speech perception abilities and subjective benefits are reported, as well as benefits in the quality of life. A correlation with individual factors is provided in order to define the impact of the different variables on outcomes.

\section{Materials and methods}

The sample was composed of 30 prelingually deafened adult patients, 18 males and 12 females, median age 35 years (IQR (interquartile range): 28-42, range: 1654 ) of a group of 36 prelingually deafened adult patients $(83 \%)$ consecutively submitted to unilateral cochlear implantation at the ENT Unit of the University of Pisa (Italy), during the period from July 1999-July 2011. All prelingually deafened adult patients implanted in our institution were oral language users and consistently used hearing aids before implantation. The 30 patients enrolled in the study are those who gave their consent to participate to the study. Among the 6 implanted patients not included in the study sample, one is a not user, one has not come for follow-up at our centre for many years and the others do not come frequently for follow-up visits, as they live far from the centre.

Pre-operatively, all patients were submitted to comprehensive audiological evaluation, including a speech perception test ${ }^{13}$ without lip-reading with hearing aids, neuroradiological evaluation by petrous bone high resolution computed tomography (CT) and brain and inner ear magnetic resonance (MR). Aetiology of hearing loss was also investigated by molecular analysis of the connexin 26 and 30 genes, and mitochondrial DNA A1555G mutation analysis in all cases, and PDS gene mutation analysis in patients with a large vestibular aqueduct. The most salient features of patients are summarised in Table I.

Post-operatively, during follow-up visits, all patients were assessed by pure tone audiometry in a free field with the $\mathrm{CI}$ in use and to a speech perception test ${ }^{13}$ without lipreading with the $\mathrm{CI}$ in use.

Pure-tone audiometry was conducted with an Interacoustics Clinical Audiometer AC40. When measuring the hearing threshold, both without HA and with HA, we assigned a value of $125 \mathrm{~dB}$ to any frequency threshold over the maximum output limit of the audiometer $(105 \mathrm{~dB}$ for $0.25 \mathrm{KHz}$ and $125 \mathrm{~dB}$ for 0.5 and $1 \mathrm{KHz}, 120 \mathrm{~dB}$ for $2 \mathrm{KHz}$ ). Any vibrotactile sensation was excluded. Speech perception was assessed using a speech percep-
Table I. Summary of salient patient features.

\begin{tabular}{|c|c|}
\hline & All patients \\
\hline Patients, n (\%) & $30(100 \%)$ \\
\hline Males, n (\%) & $18(60 \%)$ \\
\hline Use of hearing aids before implantation, $n$ (\%) & $30(100 \%)$ \\
\hline Oral language users, $n(\%)$ & $30(100 \%)$ \\
\hline $\begin{array}{l}\text { Presence of additional disabilities associated to } \\
\text { deafness, } \mathrm{n}(\%)\end{array}$ & $0(0 \%)$ \\
\hline Age at diagnosis (years), median (IQR) & $2.5(1-3)$ \\
\hline Age at diagnosis (years), range (min-max) & $0.5-6$ \\
\hline $\begin{array}{l}\text { Progression of hearing loss, progressive, } n(\%) \\
\text { Progression of hearing loss, stable, } n(\%) \\
\text { Presence of anomalies of the cochlea }\end{array}$ & $\begin{array}{c}19(63 \%) \\
11(37 \%) \\
0(0 \%)\end{array}$ \\
\hline \multicolumn{2}{|l|}{ Aetiology of hearing loss: } \\
\hline Genetic (Connexin 26 mutation), n (\%) & $2(7 \%)$ \\
\hline Large vestibular aqueduct syndrome, n (\%) & $3(10 \%)$ \\
\hline Prenatal infection, $\mathrm{n}(\%)$ & $4(13 \%)^{*}$ \\
\hline Postnatal infection, n (\%) & $1(3 \%)^{\star \star}$ \\
\hline Unknown, n (\%) & $20(67 \%)$ \\
\hline \multicolumn{2}{|l|}{ Cochlear Implant } \\
\hline Freedom Contour Advance, n (\%) & $11(37 \%)$ \\
\hline Nucleus Cl24M, n (\%) & $4(13 \%)$ \\
\hline Nucleus 24 Contour, n (\%) & $3(10 \%)$ \\
\hline Nucleus 24 Contour Advance, n (\%) & $10(33 \%)$ \\
\hline Cl512, n (\%) & $2(7 \%)$ \\
\hline \multicolumn{2}{|l|}{ Speech Processing Strategy } \\
\hline ACE, n (\%) & $27(90 \%)$ \\
\hline SPEAK, n (\%) & $3(10 \%)$ \\
\hline
\end{tabular}

Note: "4 patients (3 fetopathy rubella, 1 toxoplasmosis); " 1 patient (mumps at 2 years) $I Q R$, interquartile range

tion test in Italian language ${ }^{13}$ both before (with hearing aids) and after implantation (with CI) in free field, by the same speech therapist in all the patients to avoid bias, with live voice, and without lip-reading. We evaluated the disyllabic words recognition score using lists of 20 disyllabic Italian words at a level of $65 \mathrm{~dB}$.

In order to obtain information about personal factors and subjective benefits from CI, at the moment of the study setup we administered a questionnaire "University of Pisa Questionnaire" (UPQ) to all enrolled patients. This questionnaire was specifically developed by our research team and is a 40 question survey, divided into 3 sections. In the first section, pre-operative information, such as type of hearing aid, ability to have telephone conversations, perception of music and rehabilitation are collected; in the second section, the same aspects after implantation are investigated; in the third section, information about social life, education level and working life are recorded.

Patients were also submitted to the APHAB questionnaire to assess improvement in the patients' own perception of the disability and in quality of life derived from CI procedure. 
Table II. Summary of subjective benefits after implantation, collected using the UPQ.

\begin{tabular}{|c|c|c|c|c|}
\hline \multirow[t]{2}{*}{ Questions } & \multicolumn{2}{|c|}{ Before implantation } & \multicolumn{2}{|c|}{ After implantation } \\
\hline & Yes & No & Yes & No \\
\hline Have telephone conversations, n (\%) & $2(7 \%)^{*}$ & $28(93 \%)$ & $18(60 \%)^{* *}$ & $12(40 \%)$ \\
\hline $\begin{array}{l}\text { Understand television without reading } \\
\text { subtitles" }^{\prime *}, n(\%)\end{array}$ & $1(3 \%)$ & $28(93 \%)$ & $9(30 \%)$ & $20(67 \%)$ \\
\hline Listen to music ${ }^{\dagger \dagger}, \mathrm{n}(\%)$ & $16(54 \%)$ & $10(33 \%)$ & $23(77 \%)$ & $7(23 \%)$ \\
\hline With $\mathrm{Cl}$ the human voice seems to be ${ }^{\ddagger}$ & $\begin{array}{l}\text { It doesn't change } 3 \% \\
\text { More natural } 77 \% \\
\text { Metallic } 11 \% \\
\text { Shrilly } 8 \%\end{array}$ & & & \\
\hline
\end{tabular}

Note: " 1 patient can have free conversations with unfamiliar people; "* 5 patients can have free conversations with unfamiliar people; "** $3 \%$ missing data pre- and postoperatively; $+13 \%$ missing pre-operative data, $\neq 1 \%$ missing data

The questionnaire was administered both before and after implantation at the moment the study was initiated. Quality of life $(\mathrm{QoL})$ was measured in all the patients after implantation and at the moment of study initiation by using the Italian version of the Short Form-36 Health Survey, version 1 (SF36 v1). Authorisation from the company was obtained. The SF36 is a generic QoL questionnaires that, through a 36-item short form survey, assesses eight health scale scores in relation to physical functioning, role-physical, physical pain, general health, vitality, social functioning, role-emotional, mental health) ${ }^{14}$. The SF36 scores estimated from the studied sample were compared to that reported in the Italian literature for normal hearing subjects and to that reported for hearing impaired subjects ${ }^{15}$.

Finally, we studied the relationship between the results, in terms of speech perception with CI, and age at the first hearing aid fitting, progression of hearing loss, preoperative PTA without hearing aids and pre-operative PTA with hearing aids in order to find any possible associations.

The mean follow-up duration after surgery was 6.2 years, ranging from 1 to 13 years.

\section{Statistical analysis}

Statistical analysis was performed with the aim to investigate differences between the pre-operative and the postoperative speech perception abilities and health conditions of patients. The distribution of numeric variables was assessed by the Shapiro-Wilk W test for normality. Comparisons between pre- and post-CI intervention patients data were conducted using the Wilcoxon matched-pairs signed-ranks test for non-parametric distribution of continuous variables and the McNemar's chi-squared test for categorical variables. The difference between paired data was considered statistically significant with a $\mathrm{p}<0.05$. Using the quantile regression model, we examined the relationship between the post implantation open-set speech recognition score and selected patient characteristics (covariates) such as as age at first hearing aid fitting, pre-operative PTA with hearing aids and progression of hearing loss, as well as the APHAB scales and SF36 scales for the 50th percentile. Compared with the traditional linear model, quantile regression is robust for departures from normality and heteroscedasticity assumptions in the response variable ${ }^{16}$.

Statistical analyses have been performed using the statistical software Stata 12.1 (Stata Corp, College Station, Texas USA).

\section{Results}

The mean pre-operative hearing threshold in the implanted ear (pure tone audiometry - PTA between 0.5-1$2 \mathrm{KHz}$ ) was $111.08 \mathrm{~dB}$ (range $93 \mathrm{~dB}-125 \mathrm{~dB}$ ). The mean pre-operative PTA in free field with hearing aids was 54.6 $\mathrm{dB}$ (range $31.6 \mathrm{~dB}-125 \mathrm{~dB}$ ).

The mean pre-operative speech perception score was $15.7 \%$ (range $0-50$ ). Before implantation, $7 \%$ of the patients were able to have telephone conversations.

After implantation, the mean pure tone audiometry (PTA between 0.5-1-2 KHz) in free field with the speech processor on was $34.7 \mathrm{~dB}$ (range 25-51.6 dB).

With regards to speech perception skills, the mean postoperative open-set words recognition score was $60 \%$ (range $0-100 \%$ ) Two of 30 patients scored $0 \%$. The improvement in terms of speech perception was statistically significant $(\mathrm{p}=0.000)$.

After implantation, $60 \%$ of patients are able to have telephone conversations. The difference between the proportion of patients able to have telephone conversations before and after implantation was significant $(\mathrm{p}=0.000)$. The most significant data, regarding subjective benefits after implantation, collected at the UPQ questionnaire are shown in Table II.

Results of APHAB scales are reported in Table III.

The norm-based scores of the SF36 eight scales measured in prelingual deafened patients revealed a significant improvement after $\mathrm{CI}$ intervention compared to the before situation in terms of general health, social functioning and mental health as reported in Table IV.

In the post-intervention framework, a significant as- 
Table III. Results of APHAB scales before and after the cochlear implant intervention.

\begin{tabular}{lccc} 
& Pre Cl & Post Cl & p $^{*}$ \\
EC scale median (IQR) & $54.2(41.7-74.7)$ & $37.5(16.5-46.2)$ & $<0.005$ \\
BN scalemedian (IQR) & $64.3(41.8-87.0)$ & $47.8(33.7-56.2)$ & $<0.005$ \\
RV scale median (IQR) & $70.7(54.2-82.7)$ & $54.2(33.7-66.3)$ & $<0.005$ \\
AV scale median (IQR) & $8.3(1-26.8)$ & $31.7(8.3-49.8)$ & $<0.005$ \\
\hline
\end{tabular}

Note: *Wilcoxon signed-rank test, $\mathrm{Cl}$, Cochlear implant. IQR, interquartile range (25 percentile- $75^{\circ}$ percentile), $E C$, ease of communication; $B N$, background noise; $R V$, reverberation; $A V$, aversiveness

sociation was found between disyllabic word recognition scores and the Ease of Communication scale of the APHAB questionnaire $(p=0.030)$. Considering the other scales of the APHAB questionnaire and the eight scales of the SF36 questionnaires, we found no significant associations between each scale and disyllabic word recognition scores after $\mathrm{CI}$ intervention.

From the univariate quantile regression model, there are no evidence of statistically significant associations between post-implantation open-set speech recognition score and age at first hearing aid fitting, pre-operative PTA without hearing aids and pre-operative PTA with hearing aids $(p>0.05)$. Nevertheless, we found a significant association between post-implantation open-set speech recognition score and progression of hearing loss $(\mathrm{p}<0.05)$.

\section{Discussion}

In the present paper, we report the results achieved in a group of 30 oralist prelingually deafened adults, submitted to CI.

Cochlear implantation in prelingual adult patients is still a true challenge since it requires a difficult decision making process for both clinicians and patients due to the uncertainty of the outcome and the risk of obtaining poor or no improvement in speech perception and stopping to use the implant; nevertheless, an increasing number of recent studies attest the efficacy of CI even in these cases, albeit with variable results ${ }^{6-9}$ 17-19.
In a recent systematic review of the literature on effectiveness and cost-efficacy of $\mathrm{CI}$ in children and adults, we reported that cochlear implantation is both clinically- and cost-effective even in adults with prelingual deafness ${ }^{12}$.

In the sample herein, the results in terms of speech perception skills are quite satisfactory. After implantation, we recorded a significant improvement in open-set speech recognition scores: before implantation the mean open-set speech recognition score was $15.7 \%$ and after implantation it increased to $63.6 \%$. Moreover, before surgery $7 \%$ of the patients were able to have telephone conversations, while after implantation $60 \%$ of patients were able, even if at various degrees of ability.

Most of the studies reporting post-implantation results in prelingual deafness have focused on speech perception results and only a few have dealt with patient satisfaction, subjective benefits and impact of CI on the quality of life. Studies investigating the impact of cochlear implantation on the quality of life in prelingually deaf adults found that, even when the results are poor in terms of speech perception abilities, participants reported satisfaction with the CI procedure. These observations suggest that measures other than speech perception test should be used to evaluate the benefit of a $\mathrm{CI}$ in this population, and therefore benefit and performance should be viewed as two separate outcomes ${ }^{3-58920}$.

In the present study, at the UPQ questionnaire we recorded an improvement in the ability to carry out some daily life activities such as the use of the telephone and the abil-

Table IV. Comparison between the norm-based scores of the 8 SF36 domains in the sample of prelingually deafened patients before and after the cochlear implant intervention.

\begin{tabular}{lccccc} 
& \multicolumn{2}{c}{ Pre Cl } & \multicolumn{2}{c}{ Post Cl } & $\mathbf{p}^{*}$ \\
& Median & IQR & Median & IQR & 0.516 \\
Physical Functioning (PF) & 57.2 & $55.1-57.2$ & 57.2 & $55.1-57.2$ & 0.415 \\
Role-Physical). (RP) & 56.2 & $49.2-56.2$ & 56.2 & $49.2-56.2$ & 0.271 \\
Body Pain (BP) & 62.8 & $47.3-62.8$ & 62.8 & $51.6-62.8$ & 0.003 \\
General Health (GH) & 57.9 & $50.9-61.7$ & 60.3 & $54.6-61.7$ & 0.107 \\
Vitality (VT) & 53.8 & $46.7-60.9$ & 56.2 & $51.4-63.3$ & 0.026 \\
Social Functioning (SF) & 46.3 & $35.4-57.2$ & 49.0 & $40.9-57.1$ & 0.138 \\
Role-Emotional (RE) & 55.3 & $44.8-55.3$ & 55.3 & $55.3-55.3$ & \\
Mental Health (MH) & 45.9 & $39.1-55.0$ & 52.7 & $45.9-55.0$ & 0.004 \\
\hline
\end{tabular}

IQR, Interquartile Range $\left(25^{\circ}\right.$ percentile- $75^{\circ}$ percentile)

Wilcoxon signed-rank test 
ity to listen to television and music. After implantation, $60 \%$ of the patients $(n=18)$ were able to have telephone conversations and $28 \%$ of these $(n=5)$ were able to have free telephone conversations even with unknown persons. In addition, $30 \%$ of patients were able to listen to television without reading subtitles, compared to only $3 \%$ before implantation. Furthermore, $77 \%$ of patients reported that after implantation the perception of music improved and $70 \%$ of patients indicated that with CI the perception of voice was more natural than with hearing aids (see Table I).

Concerning the results of the APHAB questionnaire, we recorded significant improvement after surgery in terms of median frequency of troubles while hearing in each of the four situations investigated by the questionnaire, such as ease of communication, background noise, reverberation and aversiveness $(p<0.05)$. Substantial improvements due to CI interventions were observed for ease of communications and background noise: median benefit 24.8 (IQR: 0-49.5, $p=0.003$ ) and 16.2 (IQR: 3.7-40.5, $p=0.000)$.

With regards to the SF 36 questionnaire, our patients reported very high scores after CI intervention. The patient's own quality of life perception after CI intervention was very similar to that of the normative sample of healthy Italian subjects, and even better for some aspects. Patients scored as well as the normative healthy sample for physical health, in terms of Physical Activity, Role and Physical Health and Physic Pain, and for mental health in terms of Role and Emotional Status. Implanted prelingually deafened patients did not experience limitations or pain due to their health condition in work or domestic activities nor problems resulting from emotional status. The general health and the mental health subjective perception was better in the sample of patients with CI than that of healthy patients. Implanted patients experienced lower scores for Vitality and Social Activities as compared to healthy subjects (median score: 70 (IQR: 60-85) versus 75 (IQR: 65-85) and 81.3 (IQR: 63-100) versus 87.5 (IQR: 75-100).

When comparing the scores recorded at SF 36 in our sample to the normative sample of Italian hearing impaired patients, our sample scored better than the normative sample in every aspect except for Role and Emotional State, where they achieved the same score (see Fig. 1).

The SF36 scores obtained in our sample of prelingually deafened patients have to be interpreted with much caution, as they are related to subjective evaluations on their own perception of quality of life. Moreover, the sample is small and in some subscales we recorded a high variability in answers. The comparison between our sample and the Italian normative one has some limitations due to the selfreported conditions identifying the Italian healthy group (mean age 34.8 years, age $>65$ years $3.7 \%$, female gender $46.8 \%$ ) and the Italian hearing impaired group (mean age 63 years, age $>65$ years $50.7 \%$, female gender $45 \%$ ).

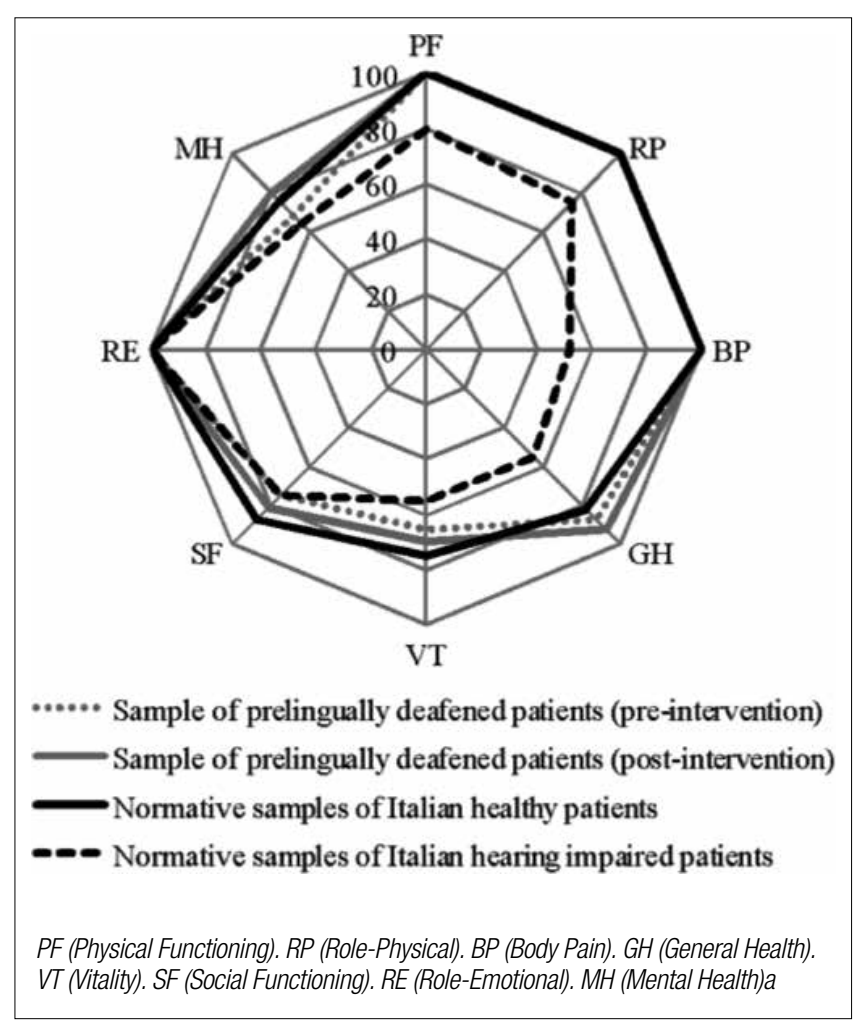

Fig. 1. Radar chart showing SF36 domains in the sample of prelingually deafened patients (pre-intervention and post-intervention) and in normative samples of Italian hearing impaired patients and healthy patients.

According to literature data, even in the reported group, patients who did not achieve improvements in terms of open set speech recognition abilities reported substantial benefits in daily life activities and in the QoL.

It is well known that the outcome after CI in prelingually deafened adults is quite variable and is best shown in the work by Klop et al (2007) ${ }^{8}$. This is likely to be related to the wide variability of the characteristics of patients. Post-implantation benefits both in adults and children is related to several individual factors, and this is mostly true in the case of pre-lingually deafened adults. Pre-operative factors that seem to make a significant contribution to post-operative hearing performance are age at onset of hearing loss and at first hearing aid fitting, speech perception performance with hearing aids 67111221 , residual hearing ${ }^{21}$, communication mode ${ }^{21}$, type of rehabilitation, educational environment ${ }^{21}$, motivation and psychological aspects 21671112 .

Moreover, Dijkhuizen et al. in 2011 reported that speech intelligibility is predictive of post-implantation hearing results in a group of prelingually deafened adults, using a specifically developed test battery ${ }^{22}$ and in a recently published paper has confirmed this ${ }^{23}$.

With regards to predictive factors in prelingually deafened adult patients, it has to be undescored that prelingually deafened adults have some peculiar aspects, as they have never experienced normal hearing in life and 
thus their neural system lacks the spatial and structural organisation for auditory processing. The literature ì suggests that the colonisation of the auditory cortex by other sensory modalities is the main limiting factor in post-implantation performance, and not the pathological degenerative changes of the auditory nerve, cochlear nucleus, or auditory midbrain ${ }^{11} 12$. Consequently the educational programs that stress oral communication as the preferred educational modality could potentially reduce the cortical colonisation of the central speech and language processing centres, and consequently the use of oral communication should be an important candidacy criterion in cochlear implantation of patients with long-term prelingual deafness. Moreover, some recent studies have explored the role of early auditory input on CI performance in prelingually deafened adults, and it was concluded that the availability of effective auditory input in early life may be the fundamental factor underlying the potential for speech perception with a CI in later life ${ }^{11} 127$.

Considering the sample herein reported, a relatively high percentage of the patients (63\%) experienced a progression of hearing loss. These patients presumably had a better auditory input early in life. We believe that this factor, associated with oralism as an exclusive mode of rehabilitation, played an important role in achieving satisfactory results reported, also in terms of open-set speech recognition abilities and consequently in the ability to have telephone conversations. In this regard, we recorded a statistically significant correlation between post-operative dysillabic word recognition score and progression of hearing loss $(\mathrm{p}<0.05)$ in our sample; nevertheless, we did not find a significant correlation between post-operative results and pre-implant hearing threshold either with or without hearing aids and age of first hearing aid fitting.

\section{Conclusions}

In conclusion, our results demonstrate that cochlear implantation is an effective option for prelingually deafened adult patients.

In accordance with the literature data, the results reported herein are quite variable but generally satisfactory, both in terms of improvement of speech perception abilities and in terms of improvement of the quality of life and patients' perception of their disability.

Indeed, some individual factors significantly affect the results, and among these effective auditory input in early life and oralist rehabilitation mode seem to be the fundamental factors underlying the potential for speech perception with a CI later in life ${ }^{67111221}$. In this regard, we found a significant correlation between the progression of hearing loss and post-operative results. Such patients had experienced a relatively good and effective auditory input early in life, and this allowed their auditory cortex to develop properly, which in turn allowed them to gain satisfactory results in terms of speech perception after implantation.

Therefore, the indications to CI and prognostic factors must be discussed on a case by case basis, taking into account mainly the progression of hearing loss, hearing aid use and results before implantation, rehabilitation mode, motivations and psychological aspects, and it is important to perform accurate counselling to provide patients with realistic expectations.

\section{References}

1 Turchetti G, Bellelli S, Palla I, et al. Systematic review of the scientific literature on the economic evaluation of cochlear implants in adult patients. Acta Otorhinolaryngol Ital 2011;31:319-27.

2 Berrettini S, Baggiani A, Bruschini L, et al. Systematic review of the literature on the clinical effectiveness of the cochlear implant procedure in paediatric patients. Acta Otorhinolaryngol Ital 2011;31:281-98.

3 Peasgood A, Brooks N, Graham J. Performance and benefit as outcome measures following cochlear implantation in non-traditional adult candidates: a pilot study. Cochlear Implants Int 2003;4:171-90.

4 Schramm D, Fitzpatrick E, Séguin C. Cchlear implantation for adolescents and adults with prelinguistic deafness. Otol Neurotol 2002;23:698-703.

5 Zwolan TA, Kileny PR, Telian SA. Self-report of cochlear implant use and satisfaction by prelingually deafened adults. Ear Hear 1996;17:198-210.

6 Kaplan DM, Shipp DB, Chen JM, et al. Early-deafened adult cochlear implant users: assessment of outcomes. J Otolaryngol 2003;32:245-9.

7 Santarelli R, De Filippi R, Genovese E, et al. Cochlear implan-tation outcome in prelingually deafened young adults. A speech percep-tion study. Audiol Neuro-otol 2008;13:257-65.

8 Klop WMC, Briaire JJ, Stiggelbout AM, et al. Cochlear implant outcomes and quality of life in adults with prelingual deafness. Laryngoscope 2007;117:1982-7.

9 Chee GH, Goldring JE, Shipp DB, et al. Benefits of cochlear implantation in early-deafened adults: the Toronto experience. J Otolaryngol 2004;33:26-31.

10 Bosco E, Nicastri M, Ballantyne D, et al. Long term results in late implanted adolescent and adult CI recipients. Eur Arch Otorhinolaryngol 2013;270:2611-20.

11 Teoh SW, Pisoni DB, Miyamoto RT. Cochlear implantation in adults with prelingual deafness. Part I: Clinical results. Laryngoscope 2004;114:1536-40.

12 Teoh SW, Pisoni DB, Miyamoto RT. Cochlear implantation in adults with prelingual deafness. Part II. Underlying constraints that affect audiological outcomes. Laryngoscope 2004;114:1714-9.

13 Burdo S. Protocollo comune di valutazione dei risultati in audiologia riabilitativa. I Care 1997.

14 Ware JE, Sherbourne CD. The MOS 36-Item Short-Form Health Survey (SF-36). I. Conceptual framework and item selection. Med Care 1992;30:473-83.

15 Apolone G, Moscone P, Ware JE. Questionario sullo stato di 
salute SF-36, Manuale d'uso e guida all'interpretazione dei risultati. Milano: Guerini e Associati; 1997.

16 Koenker R, Hallock KF. Quantile regression: an introduction. The Journal of Economic Perspectives 2001;15:143-56.

17 Arisi E, Forti S, Pagani D, et al. Cochlear implantation in adolescents with prelinguistic deafness. Otolaryngol Head Neck Surg 2010;142:804-8.

18 Waltzman SB, Roland J, Thomas Jr, et al. Delayed implantation in congenitally deaf children and adults. Otol Neurotol 2002;23:333-40.

19 Shpak T, Koren L, Tzach N, et al. Perception of speech by prelingual pre-adolescent and adolescent cochlear implant users. Int J Audiol 2009;48:775-83.
20 Most T, Shrem H, Duvdevani I. Cochlear implantation in late-implanted adults with prelingual deafness. Am J Otolaryngol 2010;31:418-23.

21 Yang WS, Moon IS, Kim HN, et al. Delayed cochlear implantation in adults with prelingual severe-to-profound hearing loss. Otol Neurotol 2011;32:223-8.

22 Van Dijkhuizen JN, Beers M, Boermans PP, et al. Speech intelligibility as a predictor of cochlear implant outcome in prelingually deafened adults. Ear Hear 2011;32:445-58.

23 Van Dijkhuizen JN, Boermans PP, Briaire JJ, et al. Intelligibility of the patient's speech predicts the likelihood of cochlear implant success in prelingually deaf adults. Ear Hear 2016;37:e302-10.

Received: November 8, 2016 - Accepted: March 11, 2017

Address for correspondence: Francesca Forli, Audiology and Phoniatrics Unit University of Pisa, via Paradisa 2, 56126 Pisa, Italy. Tel. +39050 997500. E-mail: francesca.forli@ gmail.com 